\title{
Analysis of Mixed Method of the Effect of Dating Status on Sexual Behavior in Adolescents Grade XI at SMAXYZ Medan
}

\author{
Relevancis Krista Zagoto ${ }^{1}$, Mangatas Silaen², Ivansri Marsaulina Panjaitan ${ }^{2}$
}

Email: relevancriskistazgt@gmail.com

\author{
${ }^{1}$ Student of Master of Public Health Sciences, Helvetia Institute of Health, Medan, North \\ Sumatra, Indonesia \\ ${ }^{2}$ Lecturer for Masters in Public Health Sciences, Helvetia Institute of Health, Medan, North \\ Sumatra, Indonesia
}

Received: February 12, 2021

Received in Revised: March 17, 2021

Accepted: March 26, 2021

\begin{abstract}
Sexual behavior is any behavior that is driven by sexual desire, whether done alone, with the opposite sex or of the same sex, from feeling attracted, dating, flirting, and having sex. Dating status and sexual behavior are closely related. The increasing age of dating adolescents has an impact on increasing opportunities for sexual behavior. This study aimed to analyze the effect of dating status on sexual behavior in Grade XI at SMA XYZ Medan in 2020.This research was mixed method. The population was 413 adolescents, the sample used accidental sampling technique. For quantitative, there are 80 teenagers, including 39 boys and 41 girls. And 6 qualitative informants including teenagers who are dating, peers and teachers. Quantitative data were analyzed by using statistical tests with univariate, bivariate and triangulation. The results showed that the cross-tabulation value of the effect of dating status on sexual behavior in adolescents was $\mathrm{p}(0.000)<\alpha(.05)$. There was an effect of dating status on sexual behavior in adolescents. Based on the qualitative results, the key informants stated that they were dating and had committed various sexual behaviors with their boyfriends, while the supporting informants, namely peers, stated that they were close friends with the key informants, knew the dating status and had seen sexual behavior carried out by the key informants. The conclusion that sexual behavior in adolescents at SMA XYZ was found. It is hoped that adolescents will maintain a friendly environment in social interactions and be more active in positive activities, so that unbeneficial activities such as those related to dating and sexual behavior can be avoided.
\end{abstract}

Key words: Dating Status, Sexual Behavior

\section{Introduction}

Sexual behavior according to Sarwono (Lia, 2017) is all behavior that is driven by sexual desire, whether done alone, with the opposite sex or the same sex. The forms of this behavior can vary from feelings of attraction, dating, flirting, and have sex (Lia, 2017). According to Wulandari P Utami, "Dating is running a relationship where two people meet and carry out a series of activities together in order to get to know each other". The term dating is not known in Islam, while the term for establishing a relationship between a man and a woman before marriage, Islam only recognizes the term khitbah (proposed to marriage).

It can be concluded that dating is a series of joint activities tinged with intimacy and emotional attraction between unmarried men and women with the aim of getting to know each other and seeing the suitability of each other as a consideration before marriage (Utami, 2018). Based on 
data from the World Health Organization (2016), it is stated that around 21 million adolescent girls aged 15-19 years in developing countries experience pregnancies every year and nearly half of these pregnancies (49\%) are unwanted pregnancies. One of the causes of this pregnancy is the existence of deviant sexual behavior which tends to increase every year. One of the deviant sexual behavior is sex that is done before marriage (Ahiyanasari \& Nurmala, 2018). Based on data from the World Health Organization (2016), recorded sexual behavior in Africa, Bangladesh, India, Nepal, Yemen, Latin America and the Caribbean, as many as $40 \%-80 \%$ of women have been active in sexuality by the age of 18 years, as well as in Urganda, as many as $4 \%$ of 10 year old men said they had had sexual intercourse, $10 \%$ at 12 years of age, $22 \%$ at 14 years of age, and more than $70 \%$ at 18 years of age. Every year there are 210 million teenagers who become pregnant worldwide. Of these, 46 million of them have abortions caused by excessive lust during courtship. As a result, there are 70,000 teenage deaths due to unsafe abortions while another 4 million experience pain and disability (Krista, 2016).

Furthermore, the World Health Organization also estimates that there are 20 million incidents of unsafe abortion in the world, 9.5\% (19 out of 20 million unsafe abortion acts) of which occur in developing countries. Approximately $13 \%$ of all adolescents who have unsafe abortions end in death. In the Southeast Asia region, WHO estimates 4.2 million abortions are performed annually, and around 750,000 to 1.5 million occur in Indonesia, of which 2,500 end in death (Krista, 2016). Dating behavior can increase to sexual contact in adolescents. The stages of sexual behavior are divided into 5 (five), namely touching, dating without kissing, kissing, touching sensitive parts (breasts to genitals) and sexual intercourse (Carey). In the Indonesian Demographic Health Survey, Adolescent Reproductive Health (SDKIRR) 2017 in Indonesia, it was stated that women and men who have been dating/currently have dating behavior that have been done, including holding hands is the most common practice by women and men (64 $\%$ and $75 \%$ ), hugging (17\% women and 33\% men), kissing the lips (30\% women and 50\% men) and groping (5\% women and 22\% men). Premarital sexual behavior has consequences on health, namely sexually transmitted / transmitted infections and teenage pregnancy which can result in dropping out of school, other social sanctions or complications from pregnancy to childbirth (Promkes, 2017).

Dating can result in violence, premarital sexual behavior, unwanted pregnancy, sexually transmitted infections and others. The results of the 2017 Indonesian Demographic Health Survey include women and men claiming to have dated in high school education (92\% of women and (94\% of men). $45 \%$ of women and $44 \%$ of men started dating at the age of 15-17 years. Age for the first time sexual intercourse was 15-19 years, 59\% of women and $74 \%$ of men, the highest percentage was at the age of 17 years (19\%) both men and women (Promkes, 2017). According to Basic Health Research, 92\% of adolescents hold hands while dating, $82 \%$ kiss, $63 \%$ feel petting. These behaviors then trigger adolescents to have sexual intercourse (Riskesdas, 2013) (Ohee \& Purnomo, 2018).

According to Desiana (2015), dating status is related to the tendency of a person who influences his decision to have a relationship with the aim of choosing a life partner which is carried out by two individuals. The description of dating behavior obtained by Ekasari and Rosidawati, there is data on unhealthy dating behavior by kissing as many as 51 adolescents $(70.8 \%)$, necking as many as 55 adolescents (70.8\%), petting as many as 60 adolescents $(83.3 \%)$ and intercourse as many as 72 teenagers $(100 \%)$. This illustrates the number of adolescents who find it difficult to control their sexual urges while dating which can lead to adolescent reproductive health problems such as unwanted pregnancy (KTD), abortion, HIV-AIDS, and others (Ekasari et al., 2019). 
Research on risky sexual behavior in dating that occurs in adolescents, one of which can be caused by a lack of assertive abilities. Teenagers have not been able to communicate their feelings honestly to others, they think they do not have the right to do this (Ekasari et al., 2019).

Widjanarko's research, Husodo et al, showed that $8.2 \%$ showed a permissive response to sexual behavior in dating adolescents, namely attitudes to support sexual behavior. As many as $89.8 \%$, respondents stated that they had hugged their girlfriends as much as $81.6 \%$, respondents who said they had kissed their cheeks with their boyfriends were $73.5 \%$. A total of 2 respondents were excluded from the calculation, namely respondents who had had anal sex and had vaginal sex so that the total respondents were 47 people. Respondents who are categorized as having a high risk of having sexual intercourse are respondents who have kissed their lips, necking, petting, oral sex, and masturbating (Widjanarko et al., 2015).

This research is in line with the results of research conducted by Erni Gustina (2017) on 88 respondents, bivariate analysis using chi square and using logistic reg-receipt. shows that there is a relationship between dating status and adolescent sexual behavior $(\mathrm{p}=0.03)$. The value of RP 8.12 (95\% CI: 1.02-64.34) means that dating who is not good has a risk of 8.12 times for adolescents who have high risk sexual behavior compared to adolescents who are dating well (Ohee \& Purnomo, 2018).

This study is also in accordance with the results of research by Very Retnowati, which is a cross-sectional study with the sample in this study were adolescents aged 14-24 years who were not married. The dependent variable in this study was adolescent premarital sex and independent variables included the role of peers and status. The data were analyzed using univariate, bivariate, and multivariate logistic regression analysis. The logistic regression results showed a significant relationship between adolescents who had premarital sex behavior and dating status with an OR of 0.56. Because the OR is below one, it means that male dating behavior is a protection for premarital sexual behavior. There is also a conclusion that variables that have a significant effect on premarital sex, including dating status (74.72\%), friend motivation (67.59\%), peer influence (91.75\%), never kissing lips $(95,87 \%)$ and felt the partner's sensitive body parts $(94.30 \%)$. Teenagers who are dating are protection in having sex before marriage. The statistical results showed that there was a relationship between dating and adolescent sexual behavior $(\mathrm{OR}=0.56 ; 95 \%$ CI 0.48-0.66; $\mathrm{p}=0.000)$ (Nurfitria 2016). The high population of adolescents, accompanied by the rapid development of access to information and technology, has led to increasing problems for adolescents. One of the problems that is quite concerning for adolescents today is the decreasing age of dating and the tendency for sexual behavior to arise. Nugrah et al's research conducted with adolescent respondents from various high schools in Semarang City showed that in dating, sexual behavior of both boys and girls aged 10-24 years has shown a tendency to premarital sexual behavior (Ngurah et al., 2017).

According to research by Fatma Sylvana, downstream adolescents will find problems related to reproductive health. The reproductive health of adolescents is a marginalized group. They are not like a group of married adolescents. They hardly have much access to reproductive health information and education services. As a result, adolescents have reproductive health problems at a young age such as sexual infection / HIV / AIDS or unwanted pregnancy. Many experts state that one way to overcome adolescent sexual behavior is to provide information about reproductive health because accurate and precise information about reproductive health is not available, this condition forces them to explore on their own, even through information from the media or friends. Another factor is minimizing information about casual sex. In this case the mass media and entertainment are very important. The practice of the media, in this case the production organization, is very quick to persuade teenagers (Harahap, 2020). 
According to Nurfitria's research, Entering the era of globalization that increasingly shifts normative culture, raises its own anxiety regarding the world of adolescents. Because in this session teenagers do not have a clear place. They are not a group of children but cannot be accepted as a whole in the adult class. physically and psychologically, they have not been able to function optimally, especially in accepting the changes and shifts in globalization that have occurred. This is also emphasized in a book written by Sarwono (2015) that adolescents are a restructuring of consciousness in mental development and a period of perfecting cognitive development (awareness and integration) as well as moral development and sexual development (Utami, 2018).

Based on a qualitative research conducted by Dini Indah, et al, several perspectives from adolescents were conveyed regarding dating today. This is because teenagers are no longer ashamed to show their intimacy in public, such as holding hands, hugging, or kissing in public. Basically, other sexual activities such as physical contact to kissing were considered difficult to avoid by the majority of informants because of the process that occurred and the existence of supportive conditions. This can occur because of social changes that also change moral values and tolerance for new cultures (Indah et al., 2018).

The form of attempts to seduce sexual activity usually occurs in normal situations, not under coercion, and in conditions of commitment to dating. Based on the results of interviews conducted with several adolescents said that experiences of sexual behavior occur because this activity just happens. These results also show that the lack of adolescent ability to assertiveness. Sexual seduction also occurs not only to invite a partner to have sex, but in other forms of sexual activity, such as kissing (Indah et al., 2018).

In the course of their relationship, not all girls are able to reject their partner's wishes. One study states that by refusing sexual activity, especially sexual intercourse, adolescents will be considered refusal to avoid intimacy in dating relationships, so that in order to maintain harmony and permanence in a relationship, adolescents tend not to make rejection that can lead to quarrels and tend to accept any behavior. From the partner, including when there is rude behavior from the partner (Indah et al., 2018).

Based on the theory and research results above the findings of the researchers, it was found that adolescents with dating status are more at risk of engaging in sexual behavior which includes holding hands: touching hands, grasping, holding, hugging, hugging, hugging, necking (kissing forehead, kissing cheeks, kissing lips. , kissing the neck, kissing the breasts), Feeling sensitive body parts, namely feeling the breasts, feeling the genitals, Petting (attaching the genitals with clothes or without clothes), Oral sex or sex using the help of the oral organs, to Sexual intercourse or sexual intercourse from in adolescents who are not dating. Based on these problems, the authors are interested in taking the title "Analysis of Mix Methods of the Effect of Dating Status on Sexual Behavior in Adolescents at XYZ Medan Senior High School in $2020 "$.

\section{Methods}

This research was conducted at SMA XYZ Medan in 2020. In this study, the sample consisted of 39 male students and 41 female students with a total sample size of 80 adolescents in class XI at SMA XYZ Medan in 2020. This study used a mix Method, according to Creswell, mixed research is an approach to research that combines or connects quantitative and qualitative research methods. The strategy method that will be used is the sequential explanatory strategy.

Quantitative data analysis through univariate, bivariate analysis with Chi-Square test, qualitative data through data reduction, display data, conclusion drawing, and verification. This 
study aims to analyze the effect of dating status on sexual behavior in XI grade adolescents at SMA XYZ Medan in 2020.

\section{Results and Discussion}

Univariate Analysis

Table 1. Frequency Distribution of Respondents Based on Dating Status and Sexual Behavior of Class XI Adolescents in SMA XYZ Medan in 2020

\begin{tabular}{|c|l|c|c|}
\hline \multirow{2}{*}{ No } & \multicolumn{2}{|c|}{ Dating Status Category } & \multicolumn{2}{|c|}{ Amount } \\
\cline { 3 - 4 } & & F & \% \\
\hline 1 & Dating & 61 & 76.2 \\
\hline 2 & Not Dating & 19 & 23.8 \\
\hline & & $\mathbf{8 0}$ & $\mathbf{1 0 0}$ \\
\hline
\end{tabular}

\begin{tabular}{|c|c|c|c|}
\hline \multirow{2}{*}{ No } & \multirow{2}{*}{ Category of Sexual Behavior } & \multicolumn{2}{|c|}{ Amount } \\
\hline & & $\mathbf{F}$ & $\%$ \\
\hline 1 & Low & 24 & 30.0 \\
\hline 2 & Moderate & 25 & 31.2 \\
\hline 3 & High & 31 & 38.8 \\
\hline & Total & 80 & 100 \\
\hline
\end{tabular}

Based on the table above shows the results of the frequency distribution of respondents based on dating status, it can be seen that there are $61(76.2 \%)$ adolescents, including 31 boys and 30 girls, while $19(23.8 \%)$ teenagers are not dating. - 8 adolescents and 11 girls. While the results of the frequency distribution of respondents based on dating status, it can be seen that there are $24(30.0 \%)$ adolescents in the Low Sexual Behavior Category, including 12 boys and 12 girls. The Category of Sexual Behavior is 25 (31.2\%), including 7 boys and 18 girls and 31 (38.8\%) High Sexual Behavior, including 20 boys and 11 girls. The total number of adolescents is 80 $(100 \%)$.

\section{Bivariate Analysis}

\section{The Effect of Dating Status on Sexual Behavior in Class XI Adolescents}

Based on the research results, the effect of dating status on sexual behavior in class XI adolescents can be seen in the following table:

Table 2. The Effect of Dating Status on Sexual Behavior in Class XI Adolescents at SMA XYZ Medan in 2020

\begin{tabular}{|c|c|c|c|c|c|c|c|c|c|c|}
\hline \multirow{3}{*}{ No } & \multirow{2}{*}{$\begin{array}{c}\text { Dating } \\
\text { Status }\end{array}$} & \multicolumn{7}{|c|}{ Sexual Behavior } & \multirow{2}{*}{$\begin{array}{c}\text { p- } \\
\text { value }\end{array}$} \\
\cline { 3 - 12 } & & $\mathbf{f}$ & $\mathbf{\%}$ & $\mathbf{F}$ & $\mathbf{\%}$ & $\mathbf{f}$ & $\mathbf{\%}$ & $\mathbf{F}$ & $\mathbf{\%}$ & \\
\hline 1 & Dating & 5 & 6.2 & 25 & 31.2 & 31 & 38.8 & 61 & 76.2 & $\mathrm{p}=0.00$ \\
\hline 2 & Not Dating & 19 & 23.8 & 0 & 0 & 0 & 0 & 19 & 23.8 & 0 \\
\hline & Total & $\mathbf{2 4}$ & $\mathbf{3 0 . 0}$ & $\mathbf{2 5}$ & $\mathbf{3 1 . 2}$ & $\mathbf{3 1}$ & $\mathbf{3 8 . 8}$ & $\mathbf{8 0}$ & $\mathbf{1 0 0}$ & \\
\hline
\end{tabular}

The table above shows that there are $5(6.2 \%)$ teenagers who are dating with the low sexual behavior category, $25(31.2 \%)$ teenagers in the medium category, and 31 (38.8\%) high categories with a total of $61(76.2 \%)$ adolescents. Meanwhile, the non-dating status with the low sexual behavior category was $19(23.8 \%)$, the non-dating status with the moderate and high sexual behavior category was $0(0 \%)$ with a total of $19(23.8 \%)$ adolescents. The total number of adolescents is $80(100 \%)$. 
Based on the results of the bivariate analysis, the chi-square test results obtained value (sig) $\alpha$ $=0.000$ from the results of the analysis, it can be concluded that there is an influence between dating status on sexual behavior in XI grade adolescents at SMA XYZ Medan in 2020. The results of interviews conducted with 3 (three) key informants, 2 supporting informants, namely peers and 1 supporting informant, namely teachers. Qualitatively based on the results of indepth interviews with key informants, it was found that the key informant had committed various sexual behaviors and was supported by statements from supporting informants. Based on the results of this qualitative study, it was found that the effect of dating status on sexual behavior among adolescents in SMA XYZ Medan in 2020.

\section{The Effect of Dating Status on Sexual Behavior in Adolescents}

Based on the results of statistical tests using the chi-square test, the value (sig) $\alpha=0.000$ ( $p>$ 0.05). From the results of this analysis, it can be concluded that there is an influence between dating status on sexual behavior in XI grade adolescents at XYZ SMA Medan in 2020

Based on the results of research conducted by I Gusti Ngurah Edi Putra, et al. (2017) The increasing age of dating in adolescents has an impact on increasing opportunities for sexual behavior. This study is an observational analytic study with a cross-sectional study design. The sample size in this study was 880 school adolescents who were dating using nonprobability sampling as a sampling method. The results showed that the proportion of adolescents who had severe sexual behavior was 22.1\%. (OR $=3.0 ; 95 \% \mathrm{CI}=1.9-4.8 ; \mathrm{p}<0.001)$ (Ngurah Edi Putra et al., 2017).

This research is in line with the results of research conducted by Erni Gustina (2017) on 88 respondents, bivariate analysis using chi square and using logistic reg-receipt shows that there is a relationship between dating status and adolescent sexual behavior $(\mathrm{p}=0.03)$. The value of RP 8.12 (95\% CI: 1.02-64.34) means that dating who is not good enough has a risk of 8.12 times for adolescents who have high-risk sexual behavior compared to adolescents who are dating well Ohee \& Purnomo, (2018).

This study is also in accordance with the results of research by Very Retnowati, which is a cross-sectional study with the sample in this study were adolescents aged 14-24 years who were not married. The dependent variable in this study was adolescent premarital sex and independent variables included the role of peers and status. The data were analyzed using univariate, bivariate, and multivariate logistic regression analysis. The logistic regression results showed a significant relationship between adolescents who had premarital sex behavior and dating status with an OR of 0.56. Because the OR is below one, it means that male dating behavior is a protection for premarital sexual behavior. There is also a conclusion that variables that have a significant effect on premarital sex, including dating status (74.72\%), friend motivation (67.59\%), peer influence (91.75\%), never kissing lips $(95,87 \%)$ and felt the partner's sensitive body parts $(94.30 \%)$. Teenagers who are dating are protection in having sex before marriage. The statistical results showed that there was a relationship between dating and adolescent sexual behavior $(\mathrm{OR}=0.56 ; 95 \%$ CI 0.48-0.66; $\mathrm{p}=0.000)$ (Nurfitria, 2016).

The high population of adolescents, accompanied by the rapid development of access to information and technology, has led to increasing problems for adolescents. One of the problems that is quite concerning for adolescents today is the increasing age of dating and the tendency for sexual behavior to emerge. Nugrah et al's research conducted with adolescent respondents from various high schools in Semarang City showed that in dating, sexual behavior of both boys and girls aged 10-24 years has shown a tendency to premarital sexual behavior (Ngurah et al., 2017). 
Dating status as a type of interpersonal relationship can give birth to an attitude of free sex.This has a very significant value, where adolescents think that sexual behavior with a partner (boyfriend) is a way of strengthening their relationship and the desire to prove affection with excessive sacrifice. The results of research conducted by Nurfitria (2016) showed that adolescent sexual behavior was at risk (44.5\%) and not at risk (55.5\%). One of the factors related to adolescent sexual behavior is dating status. As many as $66.4 \%$ of adolescents have boyfriends (53.4\% are at risk of behavior) and 33.6\% of adolescents do not have girlfriends (27.0\% of potential for sexual behavior). The results calculated by Chi-Square obtained a pvalue of 0.044 ( $\mathrm{p}<5 \%$ ) (Nurfitria, 2016).

According to research by Fatma Sylvana, downstream adolescents will find problems related to reproductive health. The reproductive health of adolescents is a marginalized group. They are not like a group of married adolescents. They hardly have much access to reproductive health information and education services. As a result, adolescents have reproductive health problems at a young age such as sexual infection / HIV / AIDS or unwanted pregnancy. Many experts state that one way to overcome adolescent sexual behavior is to provide information about reproductive health because accurate and precise information about reproductive health is not available, this condition forces them to explore on their own, even through information from the media or friends. Another factor is minimizing information about casual sex. In this case the mass media and entertainment are very important. The practice of the media, in this case the production organization, is very quick to persuade teenagers (Harahap, 2020).

According to Nurfitria's research, Entering the era of globalization that increasingly shifts normative culture, raises its own anxiety regarding the world of adolescents. Because in this session teenagers do not have a clear place. They are not a group of children but cannot be accepted as a whole in the adult class. physically and psychologically, they have not been able to function optimally, especially in accepting the changes and shifts in globalization that have occurred. This is also emphasized in a book written by Sarwono (2015) that adolescents are a restructuring of consciousness in mental development and a period of perfecting cognitive development (awareness and integration) as well as moral development and sexual development (Utami, 2018).

Based on a qualitative research conducted by Dini Indah, et al, several perspectives from adolescents were conveyed regarding dating today. This is because teenagers are no longer ashamed to show their intimacy in public, such as holding hands, hugging, or kissing in public. Basically, other sexual activities such as physical contact to kissing were considered difficult to avoid by the majority of informants because of the process that occurred and the existence of supportive conditions. This can occur because of social changes that also change moral values and tolerance for new cultures (Indah et al., 2018).

The form of attempts to seduce sexual activity usually occurs in normal situations, not under coercion, and in conditions of commitment to dating. Based on the results of interviews conducted with several adolescents, they said that experiences of sexual behavior occur because this activity just happens. These results also indicate that the lack of adolescent ability to assertiveness. Sexual seduction also occurs not only to invite a partner to have sex, but in other forms of sexual activity, such as kissing (Indah et al., 2018).

In the course of their relationship, not all girls are able to reject their partner's wishes. One study states that by refusing sexual activity, especially sexual intercourse, adolescents will be considered refusal to avoid intimacy in dating relationships, so that in order to maintain harmony and permanence in a relationship, adolescents tend not to make rejection that can lead 
to quarrels and tend to accept any behavior. from the partner, including when there is rude behavior from the partner (Indah et al., 2018).

Based on the theory and research results above the findings of the researchers, it was found that adolescents with dating status are more at risk of engaging in sexual behavior which includes holding hands: touching hands, grasping, holding, hugging, hugging, hugging, necking (kissing forehead, kissing cheeks, kissing lips., kissing the neck, kissing the breasts), Feeling sensitive body parts, namely feeling the breasts, feeling the genitals, Petting (attaching the genitals with clothes or without clothes), Oral sex or sex using the help of the oral organs, to Sexual intercourse or sexual intercourse from in adolescents who are not dating. Dating status can lead to and lead to behavior that is out of control, namely sexual behavior between lovers due to frequent activities together, following trends and lifestyles that consider dating and sexual behavior to be commonplace, where things like that do not close the possibility of adolescents engaging in sexual behavior. Doing various sexual behaviors with girlfriends is a way for dating teenagers to maintain a relationship and prove affection for their partner.

\section{Research Limitation}

This study is inseparable from limitations and weaknesses. The limitation and weakness factors are factors that influence sexual behavior in this study are dating status. Meanwhile, there may be many variables related to sexual behavior but not included in the study. The variables studied were only limited to the variables within the framework of the research concept. This study uses a quantitative method with a questionnaire in the first stage of the study. There is a limitation that sometimes the answers given by the respondents do not match the real situation. This study uses a qualitative method by conducting in-depth interviews, there are limitations where the informant is afraid and hesitates if the disgrace is known by others. With the current state of the Covid-19 Pandemic, the distribution of questionnaires was carried out using the online method, not directly in schools to prevent transmission of the virus. Meeting with informants was a little difficult because there were some target informants who did not want to be interviewed because their parents did not want to / were not allowed to leave the house.

\section{Conclusion}

After the researchers finished conducting research at XYZ Medan High School in 2020, conclusions can be drawn, namely: Based on the results of the analysis of Dating Status on Sexual Behavior in Adolescents with the Chi-square test, it is found that the probability $(0.00)$ $<\alpha(0.05)$ means that Ho is rejected, meaning that there is an effect of dating status on sexual behavior in class XI adolescents at SMA Negeri 4 Medan in 2020. From the results of research that has been done, the number of respondents is 80 adolescents. Among them are 39 boys and 41 girls. The number of informants who were included in this study were 6 people, the key informants were 3 teenagers, including 2 boys and 1 girl. Supporting informants (peers) amounted to 2 teenagers, including male 1 teenager and 1 female teenager. The supporting informant (teacher) is 1 teacher, namely male. From the results of the frequency distribution of respondents based on dating status, it can be seen that there are $61(76.2 \%)$ teenagers who are male, 31 adolescents and 30 females, 19 (23.8\%) teenagers, including males. 8 teenagers and 11 girls. The total number of adolescents is $80(100 \%)$. From the results of the study, it was found that the results of the frequency distribution of respondents based on dating status indicated that there were 24 (30.0\%) adolescents with the Low Sexual Behavior Category, including 12 boys and 12 girls, 25 (31.2) Moderate Sexual Behavior Category. \%) of which 7 were male and 18 were female and $31(38.8 \%)$ of the High Sexual Behavior Category included 20 male adolescents and 11 female adolescents. The total number of adolescents is $80(100 \%)$. Based on the results of interviews with informant 1, informant 2 and informant 3 stated that 
they are dating. This is not the first time dating, often meeting girlfriends and having performed various sexual behaviors including holding hands: touching hands, holding, holding, hugging, hugging, hugging, necking (kissing forehead, kissing cheeks, kissing lips, kissing neck, kissing breasts), Feeling sensitive parts of the body, namely feeling the breasts, feeling the genitals, Petting (attaching the genitals with clothes or without clothes), but stating that they have never had oral sex or sex using the help of the oral organs, to sexual intercourse or sexual intercourse. From the results of the research that has been done, if the teenagers who are dating cannot control themselves, there will be high-category sexual behavior. Conversely, if a teenager is not dating or dating and can control himself well, it will prevent sexual behavior.

\section{References}

Ahiyanasari, C. A. E., \& Nurmala, I. (2018). the Intention of Female High School Students To Prevent Premarital Sex. Jurnal PROMKES, 5(1), 39. https://doi.org/10.20473/jpk.v5.i1.2017.39-52

Desiana, Z. (2015). Hubungan Celebrity Worship dengan Intensi Berpacaran: Studi pada Fangirl KPop (pp. 9-10). Universitas Sumatera Utara.

Ekasari, M. F., Rosidawati, \& Jubaedi, A. (2019). Pengalaman Pacaran Pada Remaja Awal. Wahana Inovasi, 8(1), 1-7.

Harahap, F. (2020). Adolescent Reproductive Health \& Media Production Organization in Indonesia: Perspective Religion and Health. 7-12. https://doi.org/10.4108/eai.7-11-2019.2294591

Indah, D., Prabandari, Y. S., \& Wahyuni, B. (2018). Asertivitas Remaja Terhadap Perilaku Seksual Pranikah ( Studi Kualitatif pada Remaja di Surabaya ). Jurnal Kesehatan Masyarakat, 2(2), 229-240.

Krista, D. (2016). Pengaruh Pola Asuh Orang Tua dan Kelompok Sebaya Terhadap Perilaku Seks Berisiko pada Remaja di SMK Negeri 1 Gunungsitoli Kota Gunungsitoli Tahun 2016. Universitas Sumatera Utara.

Lia, D. R. A. (2017). Perilaku Seksual Pada Remaja Perempuan Dengan Down Syndrome (p. 3). Universitas Muhammadiyah Purwokerto.

Ngurah Edi Putra, I. G., Erma Pradnyani, P., Astri Artini, N. N., \& Eka Purni Astiti, N. L. (2017). Factors Related to Sexual Behavior Among Teenager Dating in Denpasar City. Jurnal Kesehatan Masyarakat Andalas, 11(2), 75. https://doi.org/10.24893/jkma.11.2.75-83.2017

Nurfitria. (2016). Hubungan Status Pacaran Dengan Sikap Seks Bebas Pada Remaja Di Alun-ALun Kidul Yogyakarta. Universitas 'Aisyiyah Yogyakarta.

Ohee, C., \& Purnomo, W. (2018). Pengaruh Status Hubungan Berpacaran terhadap Perilaku Pacaran Berisiko pada Mahasiswa Perantau Asal Papua di Kota surabaya. The Indonesian Journal of Public Health, 13(2), 268-280. https://doi.org/10.20473/ijph.vl13il.2018.268-280

Promkes, S. (2017). Survei Demografi dan. 120. Available from: https://promkes.net/2018/09/08/survei-demografi-dan-kesehatan-indonesia-2017-laporanpendahuluan-indikator-utama/

Utami, W. P. (2018). Kajian Teori dan Kerangka Pemikiran (pp. 11-57). Universitas Pasundan.

Widjanarko, B., Husodo, B., Shaluhiyah, Z., \& Shinta, P. (2015). Perilaku Seksual Pacaran Remaja Di Wilayah Puskesmas Magelang Tengah. Jurnal Kesehatan Masyarakat Universitas Diponegoro, 3(1). 